\title{
The Relation between the Emirati Woman and the Gulf Drama: A Field Study 2020
}

\author{
Fawzia Al-Ali, ${ }^{1, *}$ \\ ${ }^{1}$ Faculty of Communication, University of Sharjah, United Arab Emirates \\ *Correspondence: Faculty of Communication, University of Sharjah, United Arab Emirates. E-mail: \\ f_alali@sharjah.ac.ae
}

Received: August 13, $2020 \quad$ Accepted: September 14, $2020 \quad$ Online Published: January 10, 2021

doi:10.5430/wjss.v8n1p21 URL: https://doi.org/10.5430/wjss.v8n1p21

\begin{abstract}
This study seeks to know the relation between the Emirati woman and the Gulf Drama, as well as the patterns of viewing. In addition, this study seeks to provide information for those, who are in charge of the Gulf Drama in order to get acquainted with the patterns of exposure to the Gulf Drama. And the most important result is The need to allocate large portions for women issues in the Gulf drama, discuss their problems and work to improve their mental image.
\end{abstract}

Keywords: gulf drama, Emirati woman, mental image, exposure

\section{Introduction}

During the last decade of the last century, the world witnessed a revolution in the means of communication and the information networks that facilitated the possibility of human and cultural communication, especially after the spread of satellite channels. In light of the increasing number of satellite channels, whether Arab or foreign, with its various contents of entertainment, television drama has emerged with its various kinds; such as films, series and plays with the ability to attract large numbers of viewers, and accordingly, viewing these TV dramas became a daily habit for many people (Alhedaithy, 2011).

Moreover, a woman's situation is the result of the environment in which she lives with all its economic, political, cultural and religious dimensions. Nowadays, the Arab woman, with her fellows in the Arab countries, shares many characteristics, but she has a unique situation within the frame of our Islamic heritage and values. A woman suffers from problems, which hinder her full global and regional participation that requires maintaining the Arab identity and cultural privacy. Thus, the role of media in general and the drama in particular, is highlighted in terms of forming the public opinion and directing the extent of what can be made by the drama in terms of changing the image of the media advanced woman and correcting this image in order to highlight the social and civilizational roles that have been played by her throughout her long history (Khalifa, 1999).

\subsection{Problem of Research}

Accordingly, the topic of the relation between the Emirati woman and the Gulf drama is considered as one that is not researched before and is not dealt with in any field studies, and consequently, the researcher considered conducting a field study in order to know the relation between the Emirati woman and the Gulf drama by providing precise information for those, who are in charge of making decisions on the educational needs of the Emirati woman through the Gulf Drama( Al-Dhahiri 1989).

\subsection{Importance of Research}

This research derives its importance from the importance of the Emirati woman in her community, where she represents the main basis. This study is considered as the first in its type as there is not any study conducted before on the Gulf Drama and the Emirati woman. This study seeks to know the relation between the Emirati woman and the Gulf Drama, as well as the patterns of viewing. In addition, this study seeks to provide information for those, who are in charge of the Gulf Drama in order to get acquainted with the patterns of exposure to the Gulf Drama. 


\subsection{Objectives of Study}

Objectives of this study are determined as follows:

- Knowing the patterns of the Emirati woman's exposure to the Gulf Drama.

- Knowing the reasons that drive the Emirati woman to use the Gulf Drama.

- Knowing the satisfactions achieved by the Emirati woman as a result of being exposed to the Gulf Drama.

- Providing those, who are in charge of the satellite channels, with information on the relation between the Emirati woman and the Gulf Drama.

\subsection{Theoretical Framework of Study}

Several researchers attempted to develop the theories, which are used in studying the phenomena of the mass media and adapting them to the study of the relation between a woman and the TV drama; including:

The Media Dependency Approach, which forms the relations of the audience and the mass media, as the degree of individuals' dependency on the mass media information is the basis of understanding the impact of media messages on the beliefs, feelings and behavior. (Makkawi and El Sayed, 1998).

Reception Model assumes that an individual, who receives information in any situation, mainly depends on the means of communication in receiving information, and it is, in turn, affected by several factors; such as the pattern of using a method, the type of content, respondent's interests and the compatibility between the content and the current trends. The process of reception is directly related to the idea of forming the meaning for the receiving audience through dealing with the readable and visual texts. (Wellman, B.2007).

The approach of uses and satisfactions assumes that the audience individuals are driven by psychological and social influences to use the mass media in order to obtain special results that are called "satisfactions". "Catz" sees that each individual in the relation between usage and satisfaction has a number of social and psychological factors, which generate certain needs for an individual through the individual's experience that starts with satisfying those needs by the mass media compared to other sources of satisfying those needs, and accordingly, an individual can choose between both the mass media or other sources, and as a result of exposure, some needs are satisfied and in this way the cycle of relation exists between the evolution of a need and an individual's decision to be exposed to mass media hoping to satisfy them. (Al-Ali, 2007).

\subsection{Previous Studies}

The researcher reviewed the previous studies that are relevant to the United Arab Emirates, and it is evident that there is shortage of researches that are directly related to this research topic in UAE; as the studies are confined to the following studies:

- Studying the Relation between the Emirati Woman and the Mass Media: The study is conducted on a sample of the UAE community consisting of 300 individuals, and the most important results of study are as follows:

$100 \%$ of the sample individuals watch TV, the most common period of watching is afternoon at a rate of $(76.6 \%)$, the hours of watching are 3 hours and more at a rate of (73\%), the most important programs watched by the sample are the cultural programs at a rate of $(32.2 \%)$, and most of the women of the sample prefer listening to the radio at a rate of $(86.6 \%)$, read newspapers at a rate of $(72 \%)$, go to the cinema $(83.2 \%)$ and use Internet $(78.2 \%)$. (El Sayed, 2001).

- Another Study on the Extent of an Emirati Woman's Exposure to the Satellite Channels in the UAE and the Most Important Results and the Recommendations are crystalized as follows:

Most of the respondents watch the satellite channels permanently at a rate of $(81.5 \%)$, the evening period got the highest rate among the channels at a rate of $(62.5 \%)$ and the most important and preferred Egyptian satellite channels are at a rate of $(60.5 \%)$, followed by the rest of the channels. The most important subjects favored by the sample are: the films and series at a rate of $(36.0 \%)$, the most important effects of exposure to satellite channels are the acquisition of skills at a rate of (51\%) followed by supporting the prevailing values in the society at a rate of $45.2 \%$. (Moussaoui's struggle, 1988).

- Another Analytical Study: Carried out by the Researcher on the Woman Programs broadcasted on the Radio Stations in UAE and Milwaukee City in the United States-A Comparative Study. The most important results and recommendations are crystalized as follows:

Non-consulting experts and specialists in the production of programs on the one hand, and on the other hand, the lack 
of programs that contain education and culture and the lack of variety of artistic templates; as the study proved that most programs are presented in the template of direct talk and the lack of women's participation in those programs that are of great concern to them. The study recommended paying attention to the women programs on the radio in $\mathrm{UAE}$ and presenting programs in various templates and not confining to a certain template, as well as consulting experts and scholars in this field in order to include the women programs in the radio stations in UAE. (Al Bayan newspaper, 2003).

- Another Study: About the Arab Gulf woman's image in the songs of the youth (Video Clips), and the most important conclusion of the study is that the image of the Arab Gulf women in the video clips is a reinforcement of a stereotype that we are accustomed to seeing in the Arab media and the Western media in general: In our belief that these stereotypes are not in the interest of the Gulf woman. The study recommended studying, analyzing and criticizing the image of the Arab woman in the video clips due to the great role played in the process of female stereotyping due to the spread size of this song.( Gharib,1988).

- A Study on the Emirati Females in the Field of Visual Media

This study is carried out on a sample of Emirati females, who work in the field of visual media. The research aimed at knowing the current and future role of the Emirati woman in the field of visual (TV) media and measuring the degree of their awareness, as well as the importance of their role in the field of media. The most important result of this study is that the Emirati females have a noticeable role in the field of visual media and the respondent females also do different types of work on TV, and the role played by the mass media in faking the awareness of society with all its categories; as it no longer trusts the women's capabilities, and the women lost their desire of self-proving and they no longer trust their abilities. (Reza, Al-Abd, 1988).

While the study of Fawzia Fahim focused on analyzing a sample of series shown on Al-Oula Channel in the Egyptian TV, and the most important result of study is that the series dealt with women through $81 \%$ of the age of series, and she appeared generally in secondary roles; such as a servant and a dancer, and they focused on the man-woman relation. (alal, 2007).

- The study of Suha Zaki Abdelkader: The researcher analyzed the TV series and a sample of the woman-oriented programs. The most important results of the research are as follows: The female characters represent $30 \%$ of the total number of characters covered by the TV programs and the topics revolve around the presence of the woman in the house and the appearance of men in the workplace, and that these series address the upper classes above the medium one. (Kader Zaki, 1986).

- Noha Al-Abd's study sought to know the Arab woman's usages for the Arab satellite channels and their achieved satisfactions. Moreover, the study is applied to a purposive sample consisting of (400) female respondents of the Arab delegations, who reside in Egypt. The study reached a group of results; topmost of which are: Watching the satellite channels by the female respondents (sample of study) are distributed as follows: Always (48.3\%), sometimes $(41.8 \%)$ and rarely $(10 \%)$. There are statistically significant differences among the female respondents (sample of study) according to their different levels of education in terms of the satisfactions achieved for them as a result of being exposed to the satellite channels. (Shahin, 2001).

- Comments on the Previous Studies

The review of previous studies reveals that it has focused on the study of private satellite channels in terms of being methods and also focused on the satisfactions achieved from watching these channels. Some Arab studies have also been concerned about the negative impacts of satellite channels and the audience with all its different types, while they have not paid much attention to the positive values that these programs can broadcast and their impact on the audience.

The researcher benefited from previous studies in forming the theoretical framework of the research through the theories suggested by the researcher that she considered beneficial when applying them to the study.

The researcher benefited from previous studies that used the Media Dependence Model, the Reception Model, the Usages and Satisfactions Model. These models helped in formulating the objectives, questions and hypotheses of the study through the results of those studies.

\subsection{Questions of Research}

This study seeks answering the following questions:

First: Inquiries of Study: 
1. What is the extent of the Emirati woman's keenness to exposure to the Gulf drama?

2. What is the average time spent by the Emirati woman on the exposure to the Gulf drama?

3. What kind of subjects preferred to the Emirati woman through exposure to the Gulf drama?

4. What is the purpose of the UAE woman's exposure to Gulf drama?

5. What is the extent of Emirati women's participation in talking with others about the subjects they are exposed to in the Gulf drama?

\subsection{Definition of Concepts}

First: The Gulf Drama: It includes the topics and subjects presented by the Gulf Drama; such as the series and films.

Second: Impacts of Exposure to the Gulf Drama: Meaning the satisfactions achieved by the Emirati woman as a result of her exposure to the Gulf Drama; including:

a. The current status of woman's work: - work - does not work.

b. The Educational Status: - Educated - Uneducated.

\section{Research Approach and Sample}

This study is based on the use of Descriptive Survey to answer the questions of studies. The descriptive survey helps in using the numbers to reach specific results, not only with respect to the presence or absence of a variable, but also the degree of being affected by other variables, as well as the possibility of subjecting data to statistical analysis.

According to this research, the study seeks to identify the relationship between Emirati women and the Gulf drama and the habits of exposure to drama. It also seeks to uncover the relationships between the facts that are derived and some of the social and communicational facts of the respondents, the social status, the educational level and the age.

This research depends on the statistical tactic in the standard number and deducing the indicators used in inference, while using qualitative analysis as well as statistical analysis to complete aspects of the study and to interpret the results.

The researcher relied on the survey method in terms of the values of measurement in a field study within the framework of the survey approach through a sample consisting of (200) individuals from the UAE community in the simple random sampling method, so that the results of the original community are included in the survey as they are one of the categories that are highly used in the survey researches, which seek studying the audience's views and trends, as well as the impact of the Gulf drama in the UAE by using the newspaper interpersonal interview.(Al-Ali, 1998).

\section{Results of Study}

Table 1. Distribution of the Sample Individuals as Per the Extent of Exposure to the Gulf Drama on the Satellite and National Channels, and the Nationality

\begin{tabular}{lllllll}
\hline \multirow{2}{*}{ Extent of Exposure } & Local & & Non-Local & \multicolumn{3}{c}{ Total } \\
\cline { 2 - 7 } & Number & $100 \%$ & Number & $100 \%$ & Number & $100 \%$ \\
\hline Regularly & 100 & 86 & 75 & 88 & 175 & 87.5 \\
Sometimes & 15 & 13.0 & 10 & 11.7 & 25 & 12.5 \\
No exposure & -- & -- & -- & -- & -- & -- \\
Total & 115 & 115 & 75 & 100 & 200 & 100 \\
\hline
\end{tabular}

It is evident through the previous table that:

- Emirati women are keen to watch the Gulf drama regularly at a rate of $(87.5 \%)$, which represents the first place, followed by "sometimes" at a rate of (12.5\%), which represents the second place.

- The detailed tables showed that there was no effect on the variable of education, social status and nationality regarding the degree of exposure to Gulf drama

- All the sample individuals are equal, which indicates the extent of the woman's interest, in general, in watching the Gulf drama and its importance to meet their needs. 
- This result is consistent with the results of previous studies in the field of Emirati woman in terms of exposure to programs in general, such as the study of Amna Al-Zahery, the study of Dr. Amna Khalifa and the study of the researcher conducted on the Emirati woman and her exposure to television programs in 2001 and the Gulf series. (Mowed. 2001).

Table 2. Shows the Sample Individuals' Distribution as per the Average Hours of Daily Exposure to the Gulf and National Drama, as well as the Nationality

\begin{tabular}{lllllll}
\hline \multirow{2}{*}{ Extent of Exposure } & \multicolumn{2}{l}{ Local Female } & Non-Local & \multicolumn{2}{l}{ Total } \\
\cline { 2 - 7 } & Number & $100 \%$ & Number & $100 \%$ & Number & $100 \%$ \\
\hline Less than an hour & 30 & 26.0 & 35 & 41.1 & 65 & 65 \\
One to two hours & 75 & 56.2 & 45 & 52.9 & 120 & 120 \\
Three hours and above & 10 & 8.6 & 5 & 5.8 & 15 & 15 \\
According to circumstances & 0 & 0 & 0 & 0 & 0 & 0 \\
Total & 115 & 100 & 85 & 100 & 200 & 200 \\
\hline
\end{tabular}

It is evident through table 2 that there are several results; topmost of which are:

- The average of daily exposure hours to the Gulf drama was between one and two hours, and it ranked at a rate of $65.2 \%$ compared to $52.6 \%$ for non-local female. The second place was less than 1 hour with $26.0 \%$ for the local female and $(41.1 \%)$ for the non-local female.

- And this indicates the large number of hours of spent by the local female to the Gulf drama more than the non-local female.

- At the overall level, it was found that there were no differences between the local and non-local female in relation to the hours of exposure and the statistical significance reached at a level of confidence $95 \%$. As for the educational situation, there were differences among the sample individuals, who were exposed to Gulf drama, as the viewing rate among the educated females (85.4\%), compared to (62\%) of the uneducated females, which are substantial differences that are statistically significant at confidence level of $95 \%$. This is due to the extent to which educated women can benefit from watching the Gulf drama.

Table 4. Distribution of the Sample Individuals as per the Topics Watched in the Gulf and Local Drama and Nationality

\begin{tabular}{lcccccc}
\hline \multirow{2}{*}{ Extent of Exposure } & \multicolumn{2}{l}{ Local Female } & \multicolumn{2}{c}{ Non-Local } & \multicolumn{2}{c}{ Total } \\
\cline { 2 - 7 } & Count & Percentage \% & Count & Percentage \% & Count & \%Percentage \\
\hline Social Topics & 95 & 82.6 & 75 & 88.2 & 170 & 85 \\
Economic Topics & 5 & 4.3 & 18 & 21.1 & 68 & 34 \\
Cultural Topics & 26 & 22.6 & 32 & 37.6 & 58 & 29 \\
Educational Topics & 45 & 39.1 & 65 & 76.4 & 110 & 55 \\
Historical Topics & 38 & 33.0 & 30 & 53.2 & 68 & 34 \\
Psychological Topics & 75 & 56.2 & 65 & 76.4 & 140 & 70 \\
Other, mention. & 0 & 0 & 0 & 0 & 0 & 0 \\
Total & 115 & 100 & 85 & 100 & 200 & 100 \\
\hline
\end{tabular}

Data of table 4 reveal several results:

- Local and non-local females were equal in terms of their preference for watching topics in the Gulf Drama, as both samples indicated their preference for social topics at a rate of $85 \%$, which ranked first, followed by psychological topics at a rate of $70 \%$, and ranked second, followed by the educational subjects at a rate of $55 \%$, followed by a relatively big difference for both the economic and historical subjects at a rate of $34 \%$. The cultural topics ranked last at a rate of $(29 \%)$. There is no difference between local and non-locals in terms of their preference for social issues and psychological subjects, which ranked first and second. This is indicative of the extent to which UAE women are generally interested in watching social and psychological issues in Gulf drama, perhaps to meet a certain need they have (Khaliah, 2002). 
- At the level of detailed tables, there are no statistically significant differences at level of confidence (95\%) in relation to the UAE women's interest in social and psychological issues, whether at the level of the local or non-locals, educated or non-educated women. The converging rates reached (45\%), (43\%) for both samples in terms of the social subjects, $(37 \%)$ and $(35.3 \%)$ for the psychological ones.

- This result differed with the results of previous studies conducted, including the study of the same researcher in relation to the Woman's Relation to Mass Media in 2002, where the educational programs received (8.0\%). (Al-Dhaheri, 1998).

Table 5. Distribution of the Sample Individuals as per the Objective of Exposure to the Gulf and National Drama, and Nationality

\begin{tabular}{lcccccc}
\hline \multirow{2}{*}{ Extent of Exposure } & \multicolumn{2}{l}{ Local Female } & \multicolumn{2}{c}{ Non-Local } & \multicolumn{2}{c}{ Total } \\
\cline { 2 - 7 } & Count & Percentage \% & Count & Percentage \% & Count & \%Percentage \\
\hline To obtain beneficial information. & 55 & 47.8 & 62 & 72.9 & 109 & 54.5 \\
In order to know how to deal with & 10 & 8.6 & 45 & 52.9 & 55 & 27.5 \\
difficult situations. & & & & & & \\
Entertainment and relaxation. & 42 & 36.5 & 58 & 68.2 & 100 & 50 \\
In order to know the events from my & 8 & 6.9 & 5 & 4.3 & 13 & 6.5 \\
place. & & & & & & 0 \\
According to circumstances. & 0 & 0 & 0 & 0 & 0 & 0 \\
Total & 115 & 100 & 85 & 100 & 200 & 100 \\
\hline
\end{tabular}

It is evident through table 5 That:

- The objective of obtaining beneficial information ranked first among the objectives of the Emirati woman, followed by getting exposure to Gulf drama at a rate of $(54.5 \%)$, followed by the objective of entertainment and relaxation at a rate of $(50 \%)$. Results indicated that the aim of being exposed to the Gulf Drama is to deal with difficult situations at a rate of $(27.5 \%)$, which ranked third.

- At the level of local and non-local females, it is found that there are no statistically significant differences at confidence level $95 \%$ in terms of the exposure objective, which is to obtain beneficial information at a rate of (47.8\%) and $(72.9 \%)$, followed by the objective of entertainment and relaxation at a rate of $(36.5 \%)$ and $(68.2 \%)$.

- At the level of the detailed tables, there were also significant differences at confidence level of $95 \%$ between the educated and the non-educated woman with regard to the goal of exposure to obtain information, where it was found that the rate of educated who were exposed to drama for this objective, which reached (45\%) compared to (21\%) for the non-educated women. This, if anything, indicates the extent to which the educated women are interested in benefiting from watching the Gulf drama and providing her with the information that is beneficial to her life in contrast to the uneducated woman.

Table 6. The Extent of the Emirati Woman's Discussion for the Topics to Which She Is Exposed in the Gulf and Local Drama and the Nationality

\begin{tabular}{lllllll}
\hline \multirow{2}{*}{ Extent of Exposure } & \multicolumn{2}{l}{ Local Female } & \multicolumn{3}{c}{ Total } \\
\cline { 2 - 7 } & Number & $100 \%$ & Number & $100 \%$ & Number & $100 \%$ \\
\hline Yes & 112 & 97.3 & 80 & 94.1 & 192 & 96 \\
No & 3 & 206 & 5 & 5.8 & 8 & 4.0 \\
I do not know & 0 & 0 & 0 & 0 & 0 & 0 \\
Total & 115 & 100 & 85 & 100 & 200 & 100 \\
\hline
\end{tabular}

It is evident through table 6 that:

- Emirati women often use the content they are exposed to in the Gulf drama to support social interaction with others. The percentage of respondents who answered yes reached (97.2) of the local females, compared to (94.1\%) of the non-locals and the difference between the percentages is not significant at confidence level $95 \% \mathrm{~m}$ which is evidence of the equality of both samples in the extent to which they use the content they are exposed to in discussion with 
others.

- At the level of detailed tables for the educated and non-educated, both samples are equal in the extent of use of the content through discussions with others; as the rate of both samples reached (74.1\%) and (65.5\%) respectively. The difference between the percentages is not statistically significant at $95 \%$ confidence level.

- At both the working and non-working women levels, both models are equal in their use of the extent of the drama content to speak and discuss with others. This is indicative of the ability of the Gulf drama to attract women at different levels of local, non-local, educated and non-educated females when talking about the content, where it is useful and worthy of discussion with others.

Table 7. Shows the Distribution of the Sample Individuals as per the People to Whom a Woman Talks When Discussing Topics and Nationality

\begin{tabular}{lllllll}
\hline \multirow{2}{*}{ Extent of Exposure } & \multicolumn{2}{l}{ Local Female } & \multicolumn{3}{c}{ Non-Local } \\
\cline { 2 - 7 } & Number & $100 \%$ & Number & $100 \%$ & Number & $100 \%$ \\
\hline Husband & 15 & 13.0 & 13 & 15.2 & 28 & 14 \\
Children & 3 & 2.6 & 15 & 17.6 & 18 & 9 \\
Friends & 85 & 73.9 & 55 & 64.7 & 140 & 70 \\
Neighbors & 5 & 4.3 & 2 & 2.3 & 7 & 3.5 \\
Parents & 7 & 6.0 & 1 & 1.17 & 7 & 3.5 \\
Other, mention. & 0 & 0 & 0 & 0 & 0 & 0 \\
Total & 115 & 100 & 85 & 100 & 200 & 100 \\
\hline
\end{tabular}

It is evident through table 7 that:

- The table indicates that friends come on top of the people, to whom the Emirati woman talks in general at a rate of $(70 \%)$, and it ranked first, followed by a relatively large percentage (14\%), and ranked second, then the children at a rate of $(9 \%)$ and ranked third.

- At the level of local and non-local females, friends come in their discussion of the topics in terms of the local woman more than the non-local woman at a rate of $(73.9 \%),(64.7)$ and the difference is statistically significant at confidence level 95\% $(\mathrm{Y}=2.14)$.

- At the level of detailed tables, it is found that the educated and non-educated women reached (65.7\%) for the local woman compared to $(42.3 \%)$ for the non-local woman, and those differences are considered statistically significant at confidence level $95 \%(\mathrm{Y}=3.3)$.

- The researcher studied the extent of the correlation between the turnout of both the educated and non-educated women to discuss topics with friends by using the coefficient correlation Silberman found that the transaction reached (9.0), which means that there is a high correlation is high as both the educated and non-educated women are compatible in the discussion of topics with friends that ranked first between the educated and non-educated.

- This indicates that friends are the only and most trustworthy and comfortable source to which the women in general prefer to discuss the topics they watch in the Gulf drama.

Table 8. Shows the Distribution of the Sample Individuals as per its Regularity of Watching the Local Gulf Drama and Nationality

\begin{tabular}{lllllll}
\hline \multirow{2}{*}{ Extent of Exposure } & \multicolumn{2}{l}{ Local Female } & Non-Local & & Total \\
& Number & $100 \%$ & Number & $100 \%$ & Number & $100 \%$ \\
\hline Regularly & 35 & 30.4 & 28 & 32.9 & 63 & 31.1 \\
Sometimes & 48 & 41.7 & 33 & 38.8 & 81 & 40.5 \\
I do not care & 32 & 27.8 & 24 & 28.2 & 56 & 28.0 \\
I do not know & 0 & 0 & 0 & 0 & 0 & 0 \\
Total & 115 & 100 & 85 & 100 & 200 & 100 \\
\hline
\end{tabular}

The previous table 8 refers to several results:

- The table indicates that women are keen to follow the subjects allocated to them regularly in the Gulf drama at a rate of $(31.0 \%)$, sometimes at a rate of $(40.5 \%)$ and I do not care at a rate of $(28.0 \%)$. 
At the level of detailed tables, there are no differences between local and non-local women in terms of following the Gulf drama regularly, as the rates reached $(25.6 \%)$ and $(22.8 \%)$ respectively. There were no statistically significant differences at confidence level $95 \%$.

- We conclude that Emirati women's interest in following up the topics allocated to them regularly in the Gulf drama is still weak and requires more attention and diversity in the programs and topics presented through the Gulf drama and more awareness of the importance of these programs for Emirati women.

Table 9. Shows the Distribution of the Sample Individuals as per the Extent of Believing that Local and Gulf Drama is Interested in the Topics Relevant to the Woman and Nationality

\begin{tabular}{lllllll}
\hline \multirow{2}{*}{ Extent of Exposure } & \multicolumn{2}{l}{ Local Female } & \multicolumn{3}{c}{ Non-Local } & \multicolumn{3}{c}{ Total } \\
\cline { 2 - 7 } & Number & $100 \%$ & Number & $100 \%$ & Number & $100 \%$ \\
\hline Regularly & 78 & 67.8 & 60 & 70.5 & 138 & 69 \\
Sometimes & 25 & 21.7 & 19 & 22.4 & 44 & 22.0 \\
I do not care & 12 & 10.4 & 6 & 7.0 & 18 & 9.0 \\
Total & 115 & 100 & 85 & 100 & 200 & 100 \\
\hline
\end{tabular}

Several Results are indicated by table 9

- The sample of the study shows that the Gulf drama is concerned with the specialization of topics that target women always at a rate of $(69 \%)$, followed by first place followed by "is interested to some extent" at a relatively large rate $(22.0 \%)$ and "do not care whatsoever" at a rate of $(9.0 \%)$. At the level of local and non-local women, we find that beliefs are equal in terms of the idea that the Gulf drama is interested in the topics relevant to women's, as the rates reached $67.8 \%$ and $7.5 \%$ respectively. There are no statistically significant differences at $95 \%$ confidence level.

- Accordingly, those who are in charge of the Gulf Drama are required to exert more effort and specify more spaces and time for the topics of the Emirati woman.

Table 10. Shows the Distribution of the Sample Individuals as per the Reflection of the Emirati Woman's Image through the Local and Gulf Drama in a Real form and the Nationality

\begin{tabular}{lllllll}
\hline \multirow{2}{*}{ Extent of Exposure } & \multicolumn{2}{l}{ Local Female } & \multicolumn{3}{c}{ Non-Local } & \multicolumn{3}{c}{ Total } \\
\cline { 2 - 7 } & Number & $100 \%$ & Number & $100 \%$ & Number & $100 \%$ \\
\hline Yes & 30 & 26.0 & 21 & 24.7 & 51 & 25.5 \\
No & 85 & 73.9 & 64 & 75.2 & 149 & 74.5 \\
Total & 115 & 100 & 85 & 100 & 200 & 100 \\
\hline
\end{tabular}

Several Results are shown by table 10:

- The image reflected by the Gulf Drama is quite far from reality, as a rate of $(25.5 \%)$ of the sample individuals mentioned "yes" the drama reflected the Emirati woman's image, and a rate of (74.5\%) answered "no" it does not reflect the Emirati woman's image. At the overall level, views of the sample individuals (locals and non-locals) were equal in terms of reflecting the Emirati woman's image in a real form in the Gulf Drama; as the rates reached (18.6\%) and $(15.2 \%)$ respectively and there are no statistically significant differences between both samples at confidence level $95 \%$.

- We conclude that the Gulf Drama does not present the Emirati woman in a real form, but rather presents an image that is far from reality whether in terms of the careers, features or roles that she plays within the series, and this result is similar to the results of several previous studies; such as the one conducted by Amna Al-Zahery on The Woman's Image in the Songs of Youth" 2002, (26), the study of the researcher on the "Woman Programs on TV" in 1989 (27) and the study of Amna Khalifa on the Woman's Cultural Programs on the UAE TV in 1999. 
Table 11. Shows the Distribution of the Sample Individuals as per Viewing the Woman's Image Reflected by the Local Gulf Drama and Nationality

\begin{tabular}{lllllll}
\hline \multirow{2}{*}{ Extent of Exposure } & \multicolumn{2}{l}{ Local Female } & Non-Local & \multicolumn{3}{c}{ Total } \\
\cline { 2 - 7 } & Number & $100 \%$ & Number & $100 \%$ & Number & $100 \%$ \\
\hline Negative & 69 & 60 & 55 & 64.7 & 124 & 62 \\
Emotional and Sympathetic & 32 & 27.8 & 23 & 27.0 & 55 & 27.5 \\
Beautiful and Attractive Female & 14 & 12.1 & 7 & 8.2 & 21 & 10.5 \\
Other, mention. & 0 & 0 & 0 & 0 & 0 & 0 \\
Total & 115 & 100 & 85 & 100 & 200 & 100 \\
\hline
\end{tabular}

Several Results are shown by table 11:

- At the total level, it is evident that (62\%) believed that the Gulf drama reflected the image of women as being negative and $(60 \%)$ as emotional and sympathetic $(7.5 \%)$ and as being an attractive and beautiful female at a rate of $(10.5 \%)$.

- At the level of local and non-local females, it is found that there were no statistically significant differences between the two types, as the rate reached $(60 \%)$ and (64.7) respectively, since both samples found that the drama reflected the woman as being negative, emotional and sympathetic at a rate of $(27.8 \%)$ for the local female, and $(27.0 \%)$ for the non-local female, an attractive female (12.1\%) for the local female and $8.2 \%$ for the non-local female.

- We conclude that there is an agreement between the views of the two samples in terms of viewing the image reflected by the Gulf drama for women.

- At the level of preferential tables, it was also found that there is agreement on the image reflected by the drama of women, which is negative in both samples at the educational level between educated and non-educated women.

- This indicates that women, whether educated or non-educated, do not want to reflect the drama and its image as negative and confused on the matter, as the mass media played a pivotal role in educating women and influenced their attitudes and opinions, as women were transferred to different cultures, and explained to them the role of women as leaders and participants in the affairs of life and society, contrary to what they believed in the Gulf drama, which was for a long time representing the role of women in the past being treated as a subordinate, who has no opinion.

Table 12. Shows the Distribution of the Sample Individuals that the Woman Wants to be Reflected by the Local Gulf Drama and Nationality

\begin{tabular}{lllllll}
\hline \multirow{2}{*}{ Extent of Exposure } & \multicolumn{2}{l}{ Local Female } & \multicolumn{2}{l}{ Non-Local } & \multicolumn{3}{c}{ Total } \\
\cline { 2 - 7 } & Number & $100 \%$ & Number & $100 \%$ & Number & $100 \%$ \\
\hline Ambitious & 45 & 39.1 & 35 & 41.1 & 80 & 40.0 \\
Working Woman & 8 & 6.9 & 4 & 4.7 & 12 & 6.0 \\
Housewife & 10 & 8.6 & 9 & 10.5 & 19 & 9.5 \\
Active and productive in the society & 20 & 17.3 & 15 & 17.6 & 35 & 17.5 \\
Educated & 30 & 27.8 & 22 & 25.8 & 54 & 27.0 \\
Other, mention. & 45 & 39.1 & 35 & 41.1 & 80 & 40.0 \\
Ambitious & 8 & 6.9 & 4 & 4.7 & 12 & 6.0 \\
\hline
\end{tabular}

Several Results are shown by table 12

- The image that women want to be reflected in the Gulf drama for the Emirati woman as being ambitious had a rate of $(40.0 \%)$ at the overall level and ranked first, followed by a relative difference of "being educated" at a rate of $(27.0 \%)$ and ranked second, and the image of being active in the society had a rate of $(17.5 \%)$ and ranked third.

- At the level of detailed tables, there are no significant differences at the level of confidence 95 for the image of the woman, who want to be reflected by the drama, as being ambitious as the rates converged in both the local and non-local female samples, respectively $(35.3 \%)$ and $(32.2 \%)$.

- At the level of the educated and non-educated, it is found that there is also agreement in the opinion of the two 
groups in terms of the image that the woman seeks to be reflected by the Gulf drama and for women as being ambitious at a rate of $(41.2 \%)$ and $(46.5 \%)$.

- This indicates the desire of women to reflect the image they want by the drama Gulf as being ambitious and educated in the first place, which is missing in the Gulf drama.

Table 13. Shows the Distribution of the Sample Individuals as per the Degree of Its Benefit from Those Series and Nationality

\begin{tabular}{lllllll}
\hline \multirow{2}{*}{ Extent of Exposure } & \multicolumn{2}{l}{ Local Female } & \multicolumn{3}{c}{ Non-Local } & \multicolumn{3}{c}{ Total } \\
\cline { 2 - 7 } & Number & $100 \%$ & Number & $100 \%$ & Number & $100 \%$ \\
\hline Yes & 97 & 84.3 & 75 & 88.2 & 172 & 86 \\
No & 18 & 15.6 & 10 & 11.7 & 28 & 14 \\
Total & 115 & 100 & 85 & 100 & 200 & 100 \\
\hline
\end{tabular}

Several Results are shown by table 13:

- At the overall level, the Emirati woman believed that she benefitted from the Gulf drama at a rate of (86\%) and did not benefit at a rate of (14\%). This is evidence showing that the drama had the ability to attract women and meet their needs, since they indicated that they benefited from watching the Gulf drama. On the level of citizenship and non-citizenship, the rate of both samples was $84.3 \%$ and $28.2 \%$, and there were no significant differences between the two samples concerning their agreement on the extent of benefit.

- At the level of the detailed tables, it is shown that the educated and non-educated females are equal in the extent of benefit, as both samples indicated respectively.

- (25\%) there are no substantial differences between both rates at confidence level (95), as $\mathrm{Y}=(1.2)$

- It is concluded through the above-mentioned that the Gulf drama has an impact on the extent of a woman's view of benefiting from it and there are no substantial differences in the answers either at the level of nationality or education; as the woman believed that she benefited from the Gulf Drama, which is considered something positive in the Gulf Drama perhaps because of including topics that benefit women in general.

Table 14. Shows the Distribution of Sample Individuals as per the Benefit and Nationality

\begin{tabular}{|c|c|c|c|c|c|c|}
\hline \multirow{2}{*}{ Extent of Exposure } & \multicolumn{2}{|c|}{ Local Female } & \multicolumn{2}{|c|}{ Non-Local } & \multicolumn{2}{|l|}{ Total } \\
\hline & Number & $100 \%$ & Number & $100 \%$ & Number & $100 \%$ \\
\hline Solving daily problems facing me. & 45 & 39.1 & 41 & 48.2 & 86 & 43.0 \\
\hline Knowing the woman's life in the past. & 30 & 26.0 & 20 & 23.5 & 50 & 25.0 \\
\hline They increase skills and information that benefit me in my life. & 15 & 13.0 & 9 & 10.5 & 24 & 12.0 \\
\hline Knowing the rules of raising children. & 10 & 8.6 & 3 & 3.5 & 13 & 6.5 \\
\hline Various Knowledge for a Woman and the Personal Status Law. & 12 & 10.4 & 5 & 5.8 & 17 & 8.5 \\
\hline Being updated on fashion. & 13 & 11.3 & 7 & 8.2 & 20 & 23.5 \\
\hline Total & 115 & 100 & 85 & 100 & 200 & 100 \\
\hline
\end{tabular}

It is evident that there are several results shown by table 14 :

- A rate of (43.0\%) of the sample individuals at the overall level indicated that it benefits from the drama and solving the problems its faces daily, and it took first place, followed by "knowing a woman's life in the past" with a relatively high difference at a rate of (25.0\%) and it took third place, followed by "being updated on the fashion news at a rate of $(23.5 \%)$ and it took third place.

- At the local and non-local female level, we find that there are differences in the sample's opinion in terms of benefiting from drama through solving daily problems faced by it, as the rates appeared as follows:

- Rates are respectively: (39.1\%) against (48.2\%), which are statistically significant differences at confidence level 95 , as $(\mathrm{Y}+2.14)$.

- Accordingly, it is concluded that the most important benefits gained by a woman in general is "solving the problems she faces daily", which is considered something good, since it is evident that drama was capable of 
providing a woman with everything beneficial in her daily life, and the Gulf drama was able through its topics and contents to satisfy a small part of the woman's requirements in general, which is considered highly significant "solving the problems of her daily life".

Table 15. Shows the Distribution of Sample Individuals as per the Impacts of Exposure to the Gulf Drama and Nationality

\begin{tabular}{llllllll}
\hline Extent of Exposure & & \multicolumn{3}{l}{ Local Female } & \multicolumn{2}{l}{ Non-Local } & \multicolumn{3}{l}{ Total } \\
\cline { 3 - 7 } & & Number & $100 \%$ & Number & $100 \%$ & Number & $100 \%$ \\
\hline Cognitive Impacts & Acquiring skills and learning new things. & 53 & 46.0 & 48 & 56.4 & 101 & 50.5 \\
& Forming views on the issues. & 34 & 29.5 & 59 & 69.4 & 93 & 46.5 \\
& $\begin{array}{l}\text { Supporting the prevailing values in the } \\
\text { society. }\end{array}$ & 66 & 57.3 & 23 & 27.0 & 89 & 44.5 \\
Spiritual Impacts & & & & & & \\
& Increasing the feeling of fear. & 65 & 56.5 & 55 & 64.7 & 120 & 60 \\
& Increasing the feeling of spirituality. & 26 & 22.6 & 23 & 27.0 & 49 & 24.5 \\
& Avoiding helping others. & 34 & 29.5 & 31 & 36.4 & 65 & 32.5 \\
Behavioral Impacts & Activity and performing daily duties. & 79 & 68.6 & 67 & 78.8 & 146 & 73 \\
& Laziness and the desire not to work. & 18 & 15.6 & 18 & 21.1 & 36 & 18 \\
Total & & 53 & 46.0 & 48 & 56.4 & 101 & 50.5 \\
\hline
\end{tabular}

Several Results are shown through table 15:

- Results referred to the impacts resulting from the Emirati woman's exposure to the Gulf Drama that at the overall level, the behavioral impacts come on top of the cognitive impacts of the woman's exposure to the Gulf Drama.

- It is concluded through reviewing the cognitive, behavioral and spiritual impacts that a woman through being exposed to the drama reaches the behavioral impact, which is "activity and performing new duties that benefit a woman". Moreover, it is evident that "acquiring skills" also ranked first among the cognitive impacts, while "supporting the prevailing values" ranked third among the cognitive impacts.

- Thus, it is concluded that the most important cognitive impacts of the Gulf Drama are: Acquiring skills, forming views and attitudes, as well as supporting the prevailing values in the society.

- Moreover, the spiritual impacts achieved by the Gulf Drama to the woman are represented in "it increases the woman's feeling of fear" against "avoiding helping others".

\section{Results and Suggestions}

As for the results of study, they are concluded as follows:

- Emirati women are keen to watch the Gulf drama in an organized manner, at a rate of $(87.5 \%)$.

- Average daily exposure hours for Gulf drama were 1-2 hours at a rate of (60\%) followed by less than one hour at a rate of $(32.5 \%)$.

- The most important topics that the study sample preferred to see are the social topics, followed by the psychological subjects, followed by the other topics and a relatively large difference; such as educational subjects.

The main objectives of exposure are to obtain beneficial information, followed by entertainment. There are no differences between local and non-local females. As for the educated and the non-educated, there were substantial differences. This indicates that the educated women are interested in benefiting from watching the Gulf drama through the good contents it presents.

Discussions were held with others on the topics that women see in the Gulf drama at a rate of $(96 \%)$. The rates were similar between the local and non-local females.

- The most important individuals with whom discussions were made by the sample individuals were "the contents that are watched with friends" at a rate of $(70 \%)$ came in first place.

- In general, women are keen to follow up the subjects that are sometimes specialized in the Gulf drama at a rate of $(43.0 \%)$ compared to $(30.0 \%)$ on a regular basis, as evidenced by the weakness of women's follow-up on the subjects assigned to them in the Gulf drama. 
- The sample of the study considers that the Gulf drama is concerned with the specialization of topics targeting women.

- The most important images of women reflected by Gulf drama from the point of view of the surveyed sample is that "they are negative" at a rate of $(62.0 \%)$.

- The local and non-local females agreed on this image, as the rates reached (60.0\%) and (64.7\%) respectively.

The most important image that Emirati women want to be reflected in the Gulf drama is that they are ambitious, at a rate of $40 \%$, followed by $27.0 \%$, and the rates were similar at both the local and non-local females, as the rates reached (39.1) and (41.1) respectively.

- $86 \%$ of the sample individuals said that they benefit from the Gulf drama and the views of local and non-local females were compatible in this regard as the rates reached (84.3\%) and $28.2 \%$ respectively.

- The most important aspects of benefiting from the Gulf drama for women in general are solving the problems they face in their daily lives as the rate reached (43.0\%) and the views of the local and non-local were the same, as the rates reached $(39.1 \%)$ and $(48.2 \%)$.

The most important impacts of exposure to Gulf drama from the point of view of the studied sample were: The behavioral impacts, which took first place at a rate of $73 \%$ at the general level, followed by the spiritual impacts at a rate of $(60 \%)$ and cognitive impacts at a rate of $(50.5 \%)$.

\section{The Most Important Suggestions}

After reviewing the results of study analysis: The researcher makes a group of suggestions as follows:

1. The need to allocate large portions for women issues in the Gulf drama, discuss their problems and work to improve their mental image.

2. The necessity of raising women's awareness to follow up their programs in the Gulf drama by announcing them and encouraging women to participate in them and to know their impact and encourage them to participate positively in community issues through seminars, conferences and press interviews, and urge them to avoid focusing on marginal issues.

3. Paying attention to the uneducated women and devote more attention to them in all subjects and contents presented by the Gulf drama, and not only focusing on educated women.

4. The need to pay attention on concentration and providing the various topics needed by women; such as political education, raising children, mental health and trying to encourage illiterate women to pay attention to literacy programs, and women's associations to receive training and benefit.

5. The sample showed a lack of interest in political education and child- raising. This is evidence that the programs or subjects presented to them were not efficient enough to attract their attention and urge them to watch.

6. The need to include programs and topics for women; such as the ones of strengthening the values prevailing in society and encouraging women to pay attention to the subject of sound education for children at a time when women need such topics, as they live in the midst of a mixture of different races in society and the diversity of values, customs, traditions and cultures.

7. The need for conducting further researches and studies on the Emirati woman to get acquainted with her actual needs through the Gulf drama according to the different characteristics and levels.

\section{References}

Adly, R., \& Atef, Al-A. (1988). Women's Programs in Radio and Television. Cairo, Arab Thought House.

Alexandria (1986). Laila Hussein El Sayed: The adoption of Arab women on the media to meet their needs. Research presented to the third annual scientific conference, Arab media and women, Cairo 18/4/2001.

Alhedaithy, Z. M. (2011). The Relationships between the Arab Satellite TV Broadcasters and Their Audience. Griffith University. https://doi.org/10.25904/1912/1250

Amani, F. (2007). The use and rarefication of TV international channel for Egyptian women's. The Egyptian Journal of Public Opinion Research, Cairo University, Faculty of Information, (2). 
Amina, K. (2001). Women's Relationship to Cultural Programs in Television: A Field Study Previous reference. The paper present in third scientific conference, for media studies. Women and Media, 23.

Amna, K. (1999). Women's Relationship to Cultural Programs in Television a Field Study. Journal of Social Affairs, 1999(8).

Amna, K. Al-D. (2002). Women's Image in Arab Gulf (Video Clip). Worksheet presented to the Forum of Women and Media, Abu Dhabi / United Arab Emirates.

Fawzia, Al-A. (2007). The Relationship of UAE University Youth with Arab Film Channels and Achievement. The Egyptian Journal of Public Opinion Research, Cairo University, Faculty of Information, (2).

Fawzia, Al-A. (December 2001). The Relationship of Emirati Women to the UAE Satellite Channels. A Field Study Presented to the Third Annual Scientific Conference of the Department of Media Studies (Women and Information). Journal of Research and Studies, (26).

Hassan, E. M., \& Laila, E. (1998). Communication and Contemporary Histories. Cairo: The Egyptian Lebanese House, p. 239.

Heba, Al-S. (April 2001). The role of Emirati women in the field of visual media. A research presented to the third annual scientific conference, Arab media and women, Cairo.

Kayahara, J., \& Wellman, B. (2007). Searching for Culture-High and Low. Journal of Computer-Mediated Communication, 12(3), 824-845. https://doi.org/10.1111/j.1083

Laila, H. E. (2001). Arab women's reliance on the media to meet their needs. Research presented to the third annual scientific conference, Arab media and women, Cairo 18/4/2001.

Moussaoui's struggle. (1980). Features of social awareness of women in radio and television, Dar Al-Fikr, Cairo. The drama towards success, Al Bayan newspaper, (1493), 1/5/2003

Suha, Abd-el-K. Z. (1986). Analysis of the contents of television series. University Library House.

\section{Copyrights}

Copyright for this article is retained by the author(s), with first publication rights granted to the journal.

This is an open-access article distributed under the terms and conditions of the Creative Commons Attribution license (http://creativecommons.org/licenses/by/4.0/). 